\title{
Totally minimally invasive Ivor-Lewis esophagectomy: initial single center experience
}

\author{
Stefano de Pascale ${ }^{1}$, Federico Ghidinelli², Alessandra Nella Piccioli', Simona Borin ${ }^{1}$, Uberto Fumagalli \\ Romario $^{1}$
}

\begin{abstract}
'European Institute of Oncology IRCCS, Milan 20141, Italy.
\end{abstract}
${ }^{2}$ Spedali Civili di Brescia, Brescia 25123, Italy.

Correspondence to: Dr. Stefano de Pascale, European Institute of Oncology IRCCS, Milan 20141, Italy.

E-mail: stefano.depascale@gmail.com

How to cite this article: de Pascale S, Ghidinelli F, Piccioli AN, Borin S, Fumagalli Romario U. Totally minimally invasive Ivor-Lewis
esophagectomy: initial single center experience. Mini-invasive Surg 2019:3:18. http://dx.doi.org/10.20517/2574-1225.2019.04

Received: 18 Jan 2019 First Decision: 18 Mar 2019 Revised: 1 Apr 2019 Accepted: 30 Apr 2019 Published: 26 Jun 2019

Science Editor: Tetsu Fukunaga Copy Editor: Cai-Hong Wang Production Editor: Jing Yu

\begin{abstract}
Aim: Minimally invasive techniques for esophagectomy decrease cardiopulmonary complications and guarantee better quality of life (QoL) compared to open techniques, without compromising oncological radicality. This retrospective study compares the short-term and QoL outcomes of hybrid Ivor Lewis (HIL) and totally minimally invasive Ivor Lewis (TMIIL).
\end{abstract}

Methods: Patients with cancer of the distal esophagus and esophagogastric junction were included into (HIL) and (TMIIL) groups in the period January 2017-July 2018. General features, intraoperative and postoperative results were analyzed. The surgical radicality and number of resected nodes were also evaluated. QoL was determined preoperatively and at 7 and 90 days postoperatively with EORTC QLQ-C30 questionnaire.

Results: General features were similar in the TMIIL and HIL groups, which contained 13 and 14 patients, respectively. Median intervention duration was 360 min (range: 240-420) for TMIIL and 330 min (range: 240-400) for HIL ( $P=0.0647$ ). Median blood losses were similar for TMIIL and HIL at $100 \mathrm{~mL}$ (range: $50-400$ ) and $175 \mathrm{~mL}$ (range: 50-350), respectively ( $P=0.0831$ ); pulmonary complications were $15 \%$ and $14 \%(P=1)$ and leaks were $7 \%$ and $14 \%$ $(P=1)$ for TMIIL and HIL, respectively.

Conclusion: Our experience suggests that TMIIL esophagectomy appears to give results similar to HIL and positively influences the QoL within 90 days after surgery. Duration of surgery and anastomotic leaks are the key elements

cC) (7) $\odot$ The Author(s) 2019. Open Access This article is licensed under a Creative Commons Attribution 4.0 International License (https://creativecommons.org/licenses/by/4.0/), which permits unrestricted use sharing, adaptation, distribution and reproduction in any medium or format, for any purpose, even commercially, as long as you give appropriate credit to the original author(s) and the source, provide a link to the Creative Commons license, and indicate if changes were made. 
influencing the learning curve. Randomized controlled trials are necessary to confirm the good results obtained and to give recommendations to avoid a high rate of complications during the learning curve for this difficult technique.

Keywords: Minimally invasive esophagectomy, Ivor Lewis, esophageal cancer, thoracoscopic esophagectomy

\section{INTRODUCTION}

Esophagectomy is a complex surgical procedure that requires two- or three-field access depending on tumor location, histology, preoperative clinical staging, comorbidities, anatomy, and physiological status. Despite considerable improvements in cancer staging, patient selection and surgical results in recent decades, overall and pulmonary complication (PC) rates have remained high enough to encourage the search for alternative operative techniques that could achieve similar cure rates with less morbidity and probable better postoperative quality of life (QoL).

Many different techniques have been adopted worldwide to achieve complete tumor resection and appropriate lymphadenectomy; a minimally invasive (MI) approach is used either for the abdominal or thoracic portion of surgery time or for both ${ }^{[1,2]}$. The Ivor-Lewis (IL) esophagectomy is the universally accepted technique to resect cancers situated in the middle and distal esophagus and esophagogastric junction (EGJ).

A minimally invasive approach was considered elective by $14 \%$ of surgeons involved in a National survey on treatment of esophageal and EGJ cancer in 2007; the same survey reported an increase to $43 \%$ of surgeons in 2014. This indicates a shift towards more diffuse application of this technique for such a complex operation. It is also interesting to observe that the preferred site of the anastomosis for esophagogastroplasty has changed from cervical to intrathoracic ${ }^{[3]}$. The reason for this relevant interest in MI surgery is represented by the possible reduction of PCs and length of hospital stay (LOS) related to this approach, without negatively affecting the outcomes in terms of anastomotic leaks.

The application of laparoscopy and thoracoscopy to perform a totally MI Ivor-Lewis (TMIIL) esophagectomy follows the idea to obtain further improved results in terms of postoperative complications and QoL.

The present work reviews our initial experience with this technique and compares the short-term outcomes obtained in this group of patients with the results obtained in patients submitted to hybrid Ivor-Lewis (HIL). Data of the current literature on TMIIL are also reported and discussed.

\section{METHODS}

Since 2005, our standardized approach for patients affected by cancer of the distal esophagus and EGJ has been HIL, except in case of bulky tumors for which a relative contraindication was evidenced. From 2013 to 2016, few cases of highly selected patients were approached with TMIIL, in a stage 1 and 2a setting, according to the IDEAL recommendations [Figure 1] $]^{[4-6]}$.

From January 2017 to July 2018, in a stage 2b setting, all patients for whom the laparoscopic procedure lasted less than $3 \mathrm{~h}$, completed, as intention to treat, the thoracoscopic procedure.

The research was performed in accordance with the Declaration of Helsinki and all patients gave informed consent to the procedure.

The results obtained in consecutive patients submitted to TMIIL and HIL between January 2017 and July 2018 were retrospectively analyzed. Data were collected in a prospective database. 
Stage 1: First new procedure. Feasibility demonstrated in a small number of selected patients

Drop: Procedure not feasible, almost all patients have serious adverse events, or sur geons lose confidence

Stage 2a: Developing technique. Technical outcomes satisfactory in selected patients

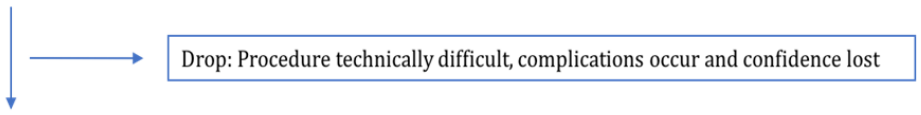

Stage 2b: Initial informal comparison with standard procedure. New procedure comparable with standard on process and short-term outcome measures

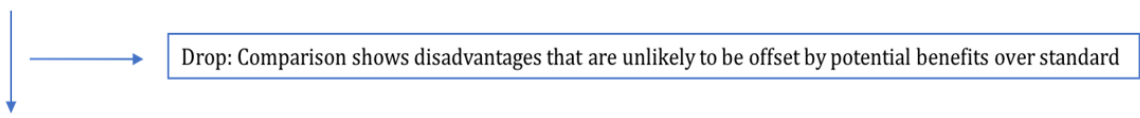

Stage 3: Full evaluation of new technique compared with standard, usually in a randomized controlled trial

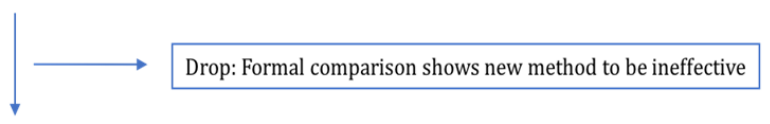

Stage 4: Monitoring to evaluate long-term outcomes, usually in the form of a national audit database/registry

Drop: Long-term outcomes hazardous

Figure 1. IDEAL recommendations framework

All procedures were performed by a single surgeon skilled in MI surgery (UFR). QoL was analyzed through the European Organization for Research and Treatment of Cancer Quality of Life Questionnaire (EORTC QLQ-C30), which was submitted to all patients the day before surgery, and at postoperative day 7 and 90.

All patients were discussed in a multidisciplinary setting following international guidelines ${ }^{[7]}$.

All the patients had a feeding jejunostomy performed either during the staging laparoscopy or during esophagectomy.

\section{Laparoscopic gastrolysis}

Dissection is performed using the hook cautery and ultrasonic device beginning with division of the gastrohepatic ligament starting distally to the crow's foot. The stomach is mobilized by dividing the left gastric vessels and short gastric vessels, and separating the right gastroepiploic arcade from the gastrocolic ligament. A standard D2-lymphadenectomy is performed. A gastric conduit is constructed by sequential firings of a linear endostapler with 45-60 $\mathrm{mm}$ cartridges parallel to the greater curvature. The first $45 \mathrm{~mm}$ cartridge is applied across the lesser curve, distally to the crow's foot, directed almost at right angle toward the greater curve; special care is required to avoid gastric tube spiralization during application of the subsequent cartridges. Interrupted 3-0 Maxon stitches are applied at the intersection of the staple lines. Feeding jejunostomy is performed in the upper left abdominal quadrant at the level of the first jejunal loop with a self-gripping barbed suture.

\section{Thoracotomy}

The right lung is excluded using a left double-lumen tube or an endobronchial blocker under fiberoptic bronchoscopic guidance, and the patient is turned to the left lateral position with a roll at the level of the tip of the scapula. A right posterolateral incision in the fifth intercostal space is performed with a section of the latissimus dorsi, sparing the serratus muscle. The lung is retracted medially. The arch of the azygos vein is divided, and the thoracic duct is selectively ligated above the diaphragm. A standard en-bloc esophagectomy 
is performed, and right paratracheal nodes are routinely removed. The esophagogastric anastomosis is performed at the apex of the right chest using a $28-\mathrm{mm}$ stapler. The gastrostomy is closed with a linear stapler. A large $360^{\circ}$ omental wrap is performed, and the pleural cavity is drained with 32 Ch drain .

\section{Thoracoscopy}

The patient is placed in the semi-prone position and the forearm flexed to improve abduction of the scapula. The chest is stabilized on the operative table using beanbag and side supports to allow rotation in a more lateral decubitus position. This is helpful to aid mediastinal exposure in patients with a protruding spine or to expedite the switch to thoracotomy if necessary. Artificial capnothorax with a pressure of $8 \mathrm{mmHg}$ is induced after first $12-\mathrm{mm}$ trocar is placed below the inferior angle of the scapula. Three additional trocars are inserted: two $12-\mathrm{mm}$ trocars in the eighth intercostal space and the middle of the vertebral border of the scapula, and a 5-mm trocar in the superior angle of the scapula. The arch of the azygos vein is divided using Hem-o-lock clips. Incision of the mediastinal pleura is performed on both sides of the esophagus, and the dissection preferably starts between the vagal trunk and the right main bronchus. This allows en-bloc lymphadenectomy of the carina with nerve preservation in most circumstances. The esophagus is then mobilized up to the level of the diaphragm and the inferior pulmonary ligament is divided. The thoracic duct is identified and ligated. After an esophagotomy on the stapled side and a gastrotomy on the small gastric curvature are performed, some stitches are used to fix the mucosa to the other layers of the esophageal wall, avoiding submucosal slippage following the technique described by Irino ${ }^{[8]}$. Gastrolysis is completed. A side-to-side anastomosis is then performed with a $30-\mathrm{mm}$ linear stapler. The enterotomies are closed with a self-gripping barbed suture. A large $360^{\circ}$ omental wrap is performed and the pleural cavity is drained.

Immediately after surgery, patients recovered in the Intensive Care Unit (ICU) until the first postoperative day.

The complications were described according to the taxonomy recently proposed by the Esophagectomy Complications Consensus Group ${ }^{[9]}$.

\section{Statistical analysis}

The Mann-Whitney $U$ test was used to compare continuous variables not normally distributed (presented as median and range). Normality of the distribution of variables was determined using the D'Agostino-Pearson test. Chi-square or Fisher's exact test, when appropriate, were used to compare categorical variables. Twotailed $P$ values are reported universally, and the significance threshold was designated at a $P$ value of 0.05 . Statistical analysis was performed with statistical software for biomedical research (MedCalc Software for Windows).

\section{RESULTS}

From January 2017 to July 2018 we performed 53 esophagectomies in patients affected by esophageal or EGJ cancers. Ten patients were submitted to the McKeown procedure, 1 patient was treated with a transhiatal esophagectomy and 3 patients with squamous cancer of the cervical esophagus underwent a pharyngolaryngo-esophagectomy. Thirty-nine patients underwent an IL procedure: 13 TMIIL, 14 HIL, and 12 OIL.

Patients submitted to TMIIL and HIL were compared according to the stage $2 \mathrm{~b}$ IDEAL recommendation. The general characteristics of the two groups are reported in Table 1. No difference was reported between the 2 groups in terms of ASA (American Society of Anesthesiologists) Classification: 9 patients in the TMIIL group and 13 patients in the HIL group were treated with a neoadjuvant or perioperative therapy; in the TMIIL group, 6 patients received chemoradiotherapy and 3 patients received preoperative chemotherapy, while in the HIL group 10 patients received neoadjuvant chemoradiotherapy and 3 patients received preoperative chemotherapy. 
Table 1. Baseline characteristics of patients undergoing TMIIL and HIL

\begin{tabular}{|c|c|c|c|}
\hline Characteristics & TMIIL $(n=13)$ & HIL $(n=14)$ & $P$ value \\
\hline Age, years, median (range) & $67.5(53-82)$ & $66(54-77)$ & 0.4265 \\
\hline Gender (M/F), $n(\%)$ & $8 / 5(61.5 / 38.5)$ & $13 / 1(93 / 7)$ & 0.1355 \\
\hline ASA, median (range) & $2[1-3]$ & $2[1-3]$ & 0.7623 \\
\hline \multicolumn{4}{|l|}{ Tumor location } \\
\hline $\mathrm{EGJ}, n(\%)$ & $8(61.5)$ & $10(71)$ & 0.6945 \\
\hline Distal esophagus, $n(\%)$ & $5(38.5)$ & $4(29)$ & \\
\hline \multicolumn{4}{|l|}{ c Stage } \\
\hline$<\|, n(\%)$ & 2 & 1 & 0.5955 \\
\hline$\geq I I, n(\%)$ & 11 & 13 & \\
\hline \multicolumn{4}{|l|}{ Neoadjuvant treatment } \\
\hline Yes, $n(\%)$ & $9(69)$ & $13(93)$ & 0.1647 \\
\hline No, $n(\%)$ & $4(31)$ & $1(7)$ & \\
\hline Chemotherapy, $n(\%)$ & $3(33)$ & $3(23)$ & 0.6550 \\
\hline Chemoradiotherapy, $n$ (\%) & $6(66)$ & $10(77)$ & \\
\hline \multicolumn{4}{|l|}{ Tumor type } \\
\hline Adenocarcinoma, $n(\%)$ & $10(77)$ & $9(65)$ & 0.6776 \\
\hline $\mathrm{SCC}, n(\%)$ & $2(15)$ & $4(28)$ & 0.6483 \\
\hline Other (\%) & $1(8)$ & $1(7)$ & 1 \\
\hline \multicolumn{4}{|l|}{ Comorbidity } \\
\hline Hypertension, $n(\%)$ & $7(54)$ & $8(57)$ & 1 \\
\hline Cardiovascular disease, $n(\%)$ & 0 & $3(21)$ & 0.2222 \\
\hline Diabetes, $n(\%)$ & $2(15)$ & $1(7)$ & 0.5955 \\
\hline
\end{tabular}

HIL: hybrid Ivor Lewis; TMIIL: totally minimally invasive Ivor Lewis

Table 2. Intraoperative variables

\begin{tabular}{llll}
\hline Characteristics & TMIIL $(\boldsymbol{n}=\mathbf{1 3})$ & HIL $(\boldsymbol{n}=\mathbf{1 4})$ & $\boldsymbol{P}$ value \\
\hline Duration of intervention median (min) (range) & $360(240-420)$ & $330(240-400)$ & 0.0647 \\
Laparoscopy converted to open surgery, $n$ (\%) & 0 & $1(7.1)$ & 0.9699 \\
Blood Loss (mL), median (range) & $100(50-400)$ & $175(50-350)$ & 0.0831 \\
Feeding Jejunostomy during esophagectomy, yes/no & $10 / 3$ & $13 / 1$ & 0.5337 \\
Duration of postoperative recovery in ICU (days), median (range) & $1(1-2)$ & $1(1-2)$ & 0.9876 \\
\hline
\end{tabular}

HIL: hybrid Ivor Lewis; TMIIL: totally minimally invasive Ivor Lewis

No differences were observed in the 2 groups for intraoperative data [Table 2], particularly for duration of intervention and blood loss.

Postoperatively, no difference was found in terms of morbidity, mortality and length of hospital stay [Table 3]. One patient in each group presented a type III anastomotic leak, (8\% vs. 7\% in TMIIL and HIL group, respectively). One patient in the HIL group (7\%) presented a type I anastomotic leak. No patients were readmitted within 90 days after surgery.

The histopathological features were similar in the 2 groups, except 1 patient in the HIL group (7\%) who had a neuroendocrine tumor. Complete pathological response was observed in 3 cases for each group, $21 \%$ and 23\%, respectively, for TMIIL and HIL. Two patients (14\%) in the HIL group presented a R1 resection for the presence of positive circumferential margins.

Results obtained from the QoL questionnaires evidenced a reduction of postoperative pain during the first 7 postoperative day for patients in the TMIIL group compared to HIL; these data were confirmed by the analysis conducted on postoperative day 90, as well for the global health status, physical functioning, and role functioning [Figure 2]. 
Table 3. Postoperative morbidity, mortality and pathologic examination

\begin{tabular}{|c|c|c|c|}
\hline Characteristics & TMIIL $(n=13)$ & HIL $(n=14)$ & $P$ value \\
\hline Postoperative complications CD $<3, n(\%)$ & $3(15)$ & $4(28.5)$ & 0.6483 \\
\hline Postoperative complications $\mathrm{CD} \geq 3, n(\%)$ & $2(15)$ & $2(14)$ & 1 \\
\hline Leaks, $n(\%)$ & $1(8 \%)$ & $2(14 \%)$ & 1 \\
\hline Pulmonary complications & $2(15)$ & $2(14)$ & 1 \\
\hline Overall morbidity, $n(\%)$ & $5(38)$ & $6(43)$ & 1 \\
\hline Mortality & 0 & 0 & n.s \\
\hline Lenght of hospital stay (day), median (range) & $13(8-24)$ & $14(8-72)$ & 0.5596 \\
\hline 90-days readmission rate, $n(\%)$ & 0 & 0 & n.s \\
\hline \multicolumn{4}{|l|}{ Pathological stage } \\
\hline$<$ II & 5 & 3 & 0.4197 \\
\hline$\geq 11$ & 8 & 11 & \\
\hline R1 resection & 0 & 2 & 0.4814 \\
\hline Lomph nodes harvested, median (range) & $23(7-71)$ & $27(7-44)$ & 0.5602 \\
\hline
\end{tabular}
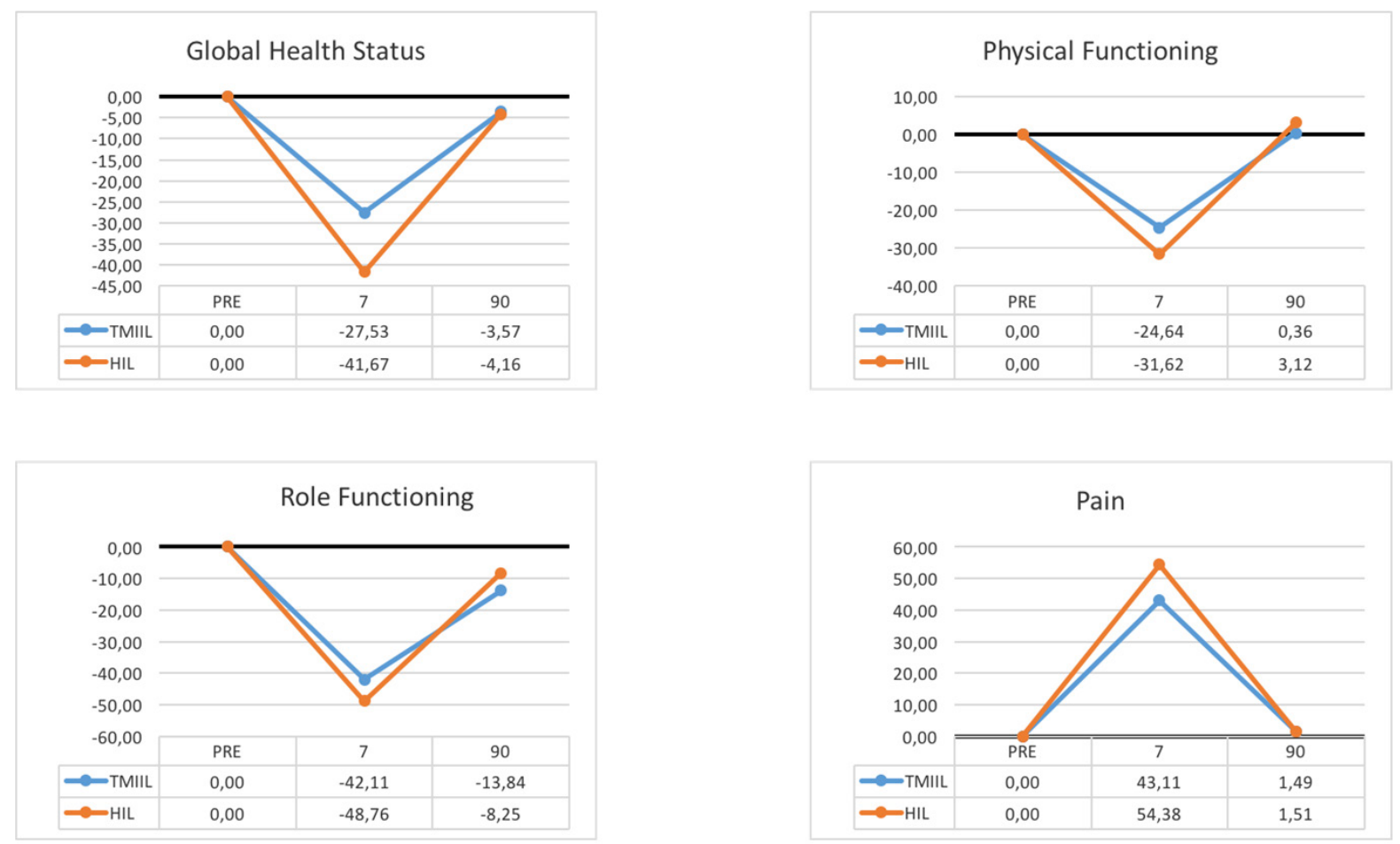

Figure 2. Quality of Life C-30 (preoperative, 7 and 90-day after surgery)

\section{DISCUSSION}

The Ivor-Lewis procedure represents the current indication for patients with cancers located in the middle, distal esophagus and EGJ; although the McKeown procedure avoids the occurrence of intrathoracic leaks, the rate of dehiscence and strictures is higher in patients with cervical anastomosis independently from the access route whether open or $\mathrm{MI}^{[10]}$. Injury to the recurrent laryngeal nerve, a complication associated with considerable morbidity, is less common if dissection in the neck is avoided ${ }^{[1,12]}$. As demonstrated by Mariette, intrathoracic anastomosis provides a lower 30-day postoperative morbidity rate compared to cervical anastomosis, and thoracotomy itself does not significantly influence postoperative morbidity ${ }^{[13]}$.

In recent years particular attention has focused on improving the postoperative results of the IL procedure through application of MI approaches. Few studies, mainly retrospective, have been published in the current literature comparing HIL and OIL. Recently, a randomized prospective study by the French Eso-Gastric 
Tumors Working Group, has been published: data obtained demonstrated a significant lower rate of PCs after HIL compared to OIL, particularly for major respiratory complications (18\% vs. 30\%, respectively, in the two groups); no differences in terms of long-term oncological outcomes were observed ${ }^{[14]}$. The logical evolution was to decrease invasiveness of IL, introducing thoracoscopy to obtain an even lower rate of postoperative complications without negatively affecting the rate of anastomotic leaks and mortality. A literature review of the last 7 years [Table 4] reports the results of retrospective comparisons between TMIIL and OIL. The principal limits of these studies are represented by their retrospective nature, the fact that sometimes they derived from subgroup analysis, and that the techniques to perform the intrathoracic anastomosis are different: the Orvil technique, the technique with a circular stapler but with hand sewn purse string, a sideto-side anastomosis with linear stapler, or a hand sewn anastomosis. Significant differences in terms of LOS, blood loss, and PCs in favor of TMIIL were reported. The rate of anastomotic leaks does not seem to be significantly different in the two groups, whereas operative time is generally longer for TMIIL.

The longer duration for TMIIL seems to be caused by the technical difficulty of performing the anastomosis ${ }^{[19]}$; a similar result was found in our experience, where duration of surgery was longer for TMIIL even if the difference was not significant. The new anastomotic technique implies a longer time but the results in terms of anastomotic leaks do not seem to be different: in our experience, with the use of a thoracoscopic sideto-side technique, the incidence of leaks was $7 \%$, lower, even if not significantly, than the results of the standardized anastomotic technique used in the HIL group.

As evidenced by Van Workum ${ }^{[24]}$, anastomotic leaks and operative time represent the key elements in the assessment achieving the learning curve plateau. In his multicenter retrospective analysis, the rate of anastomotic leaks at the end of the learning curve was $4.4 \%$, starting from an incidence of $18.8 \%$; operative time also decreased from 344 to $270 \mathrm{~min}$.

The difficulties of thoracoscopic anastomosis are demonstrated by the change in technique reported in some series during the learning curve: in Mungo's small series, they moved from a circular transoral anastomosis to a linear side-to-side anastomosis and ended again with the Orvil technique ${ }^{[25]}$.

In our experience, these elements were the principal issues considered as limiting factors for the application of TMIIL during stage 1 and 2a IDEAL recommendations.

Although the two groups are similar in terms of baseline characteristics, it is important to highlight that in the HIL group more patients were submitted to neaodjuvant treatment than in the TMIIL group. Considering the small size of our samples, it is difficult to evaluate how this might have influenced postoperative complications. This topic has been widely evaluated in the current literature and controversial results have been reported. In our experience, a direct correlation never emerged as reported by Woodard in the analysis of this element in a comparison of two groups of patients submitted to HIL ${ }^{[26]}$.

A low rate of PCs, associated with better QoL after surgery, with possible better long-term outcomes represents the benchmark for which surgeons face the hard learning curve of TMIIL. As reported in Table 4, Tapias and Wang obtained a significant reduction of respiratory complications after TMIIL; these data positively influence the postoperative course in terms of LOS as well. The principal limit of these analyses is represented by the fact that they are obtained from comparison between TMIIL and OIL, and it is widely demonstrated that laparoscopic gastrolysis has a positive impact on this type of complication.

In our analysis, no differences were observed for respiratory complications in the two groups. Data obtained from the analysis of the QoL questionnaire evidenced lower postoperative pain for patients submitted to TMIIL and a faster recovery of health global status. 
Table 4. Literature review

\begin{tabular}{|c|c|c|c|c|c|c|c|c|c|}
\hline Author & Study & Comparison & Sample & $\begin{array}{c}\text { Duration of } \\
\text { surgery, median } \\
\text { (min) (range) }\end{array}$ & $\begin{array}{l}\text { Blood loss, median } \\
\text { (mL) (range) }\end{array}$ & $\begin{array}{c}\text { LoHS, } \\
\text { median, day } \\
\text { (range) }\end{array}$ & $\begin{array}{c}\text { Pulmonary } \\
\text { complications } \\
(\%)\end{array}$ & $\begin{array}{l}\text { Leaks } \\
(\%)\end{array}$ & $\begin{array}{c}\text { 30-day } \\
\text { mortality } \\
(\%)\end{array}$ \\
\hline Bizekis et al. ${ }^{[15]}$ & Retro & $\begin{array}{l}\mathrm{TMIIL}^{\star} V S . \\
\mathrm{HIL}^{*}\end{array}$ & 15 vs. 35 & n.a & n.a & $\begin{array}{l}7 v s .9^{\circ} \\
(\text { n.a) }\end{array}$ & 27 vs. 20 & $\begin{array}{l}0 \mathrm{vs} . \\
8.5\end{array}$ & $7 v s .6$ \\
\hline Noble et al. ${ }^{[16]}$ & Prosp & 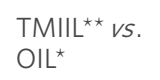 & $\begin{array}{l}53 v s . \\
53\end{array}$ & $\begin{array}{l}300(180-480) v s . \\
240^{\circ}(120-420)\end{array}$ & $\begin{array}{l}300(0-1250) v s \\
400^{\circ}(0-3000)\end{array}$ & $\begin{array}{l}12(7-91) v s . \\
12(7-101)\end{array}$ & 34 vs. 32 & 6 vs. 4 & 2 vs. 2 \\
\hline Xie et al. ${ }^{[17]}$ & Retro & $\begin{array}{l}\mathrm{TMIIL}^{\star} v s . \\
\mathrm{OIL}^{*}\end{array}$ & $\begin{array}{l}106 \text { vs. } \\
163\end{array}$ & $\begin{array}{l}249 \pm 41.7 \text { vs. } 256 \\
\pm 41.7\end{array}$ & $\begin{array}{l}187 \pm 37.8 \text { vs. } 198 \\
\pm 46.5\end{array}$ & $\begin{array}{l}11.8 \pm 6.7 v s \\
13.9^{\circ} \pm 7.3\end{array}$ & 9.4 vs. 12.9 & $\begin{array}{l}4.7 v s . \\
3.7\end{array}$ & 1.9 vs. 2.5 \\
\hline Chen et al. ${ }^{[18]}$ & Retro & $\begin{array}{l}\mathrm{TMIIL}^{\star} v s . \\
\mathrm{OIL}^{*}\end{array}$ & $\begin{array}{l}59 v s . \\
59\end{array}$ & $\begin{array}{l}250(210-320) v s . \\
200^{\circ}(170-250)\end{array}$ & $\begin{array}{l}190(150-420) v s . \\
420^{\circ}(250-550)\end{array}$ & $\begin{array}{l}9(7-19) v s \\
15^{\circ}(10-28)\end{array}$ & 8 vs. 12 & 4 vs. 5 & n.a \\
\hline Sihag et al. ${ }^{[19]}$ & Retro & $\begin{array}{l}\text { TMIIL n.a } v s . \\
\text { OIL.a }^{\text {n.a }}\end{array}$ & $\begin{array}{l}600 \text { vs } \\
1291\end{array}$ & $\begin{array}{l}453(357-546) v s \\
340^{\circ}(278-415)\end{array}$ & n.a & $\begin{array}{l}8(7-14) v s . \\
10^{\circ}(8-16)\end{array}$ & 29.7 vs. 25.4 & $\begin{array}{l}13.8 v s . \\
10.5\end{array}$ & $2.7 v s .4$ \\
\hline Tapias et al. ${ }^{[20]}$ & Retro & $\begin{array}{l}\mathrm{TMIIL}^{\star} v s . \\
\mathrm{OIL}^{\star \star \star}\end{array}$ & $\begin{array}{l}56 v s . \\
74\end{array}$ & $\begin{array}{l}337 \pm 48.3 \text { vs. } 361 \\
\pm 83.1\end{array}$ & $\begin{array}{l}200(140-200) v s . \\
250^{\circ}(150-400)\end{array}$ & $\begin{array}{l}7(6-7) v s . \\
9^{\circ}(8-11)\end{array}$ & 8.9 vs. $29.7^{\circ}$ & $\begin{array}{l}0 v s . \\
1.4\end{array}$ & 0 vs. 2.7 \\
\hline Wang et al. ${ }^{[21]}$ & Retro & $\begin{array}{l}\mathrm{TMIIL}^{*} v s . \\
\mathrm{OIL}^{*}\end{array}$ & $\begin{array}{l}334 \text { vs. } \\
285\end{array}$ & $\begin{array}{l}251 \pm 26.4 v s \\
240 \pm 26.4\end{array}$ & $\begin{array}{l}178 \pm 55 \text { vs. } 181 \pm \\
64.8\end{array}$ & $\begin{array}{l}12.9 \pm 3.9 \\
\text { vs. } 14^{\circ} \pm 4\end{array}$ & 9.9 vs. $21.4^{\circ}$ & $\begin{array}{l}4.2 v s . \\
4.2\end{array}$ & $\begin{array}{l}0.9 v s . \\
1.4\end{array}$ \\
\hline Straatman et al. ${ }^{[22]}$ & Retro & TMIIL & 282 & $333 \pm 98$ & $242 \pm 228$ & $12(9-24)$ & 13.1 & 15.2 & 2.1 \\
\hline Qi et al. ${ }^{[23]}$ & Retro & 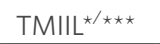 & 530 & $266(213-321)$ & $200(150-300)$ & $13(11-16)$ & 27.1 & 13.8 & 1.7 \\
\hline
\end{tabular}

${ }^{\star}$ Transthoracic circular anastomosis end to side (anvil inserted transthoracically); ${ }^{\star *}$ Transthoracic circular anastomosis end to side $\left[\right.$ Transorally inserted anvil OrVil( $\left.\left.{ }^{\mathrm{TM}}\right)\right]_{;}{ }^{\star \star \star}$ Hand-sewn intrathoracic anastomosis, $P<0.05$. n.a: not available

Data obtained in a recent multicenter randomized prospective analysis of QoL of patients submitted to MI esophagectomy are associated with better mid-term, 1-year QoL compared to open esophagectomy. For the authors, all differences between the groups in the specific domains result in a clinically important difference that is best understood for the pain domain due to post-thoracotomy pain. The improvement of QoL after 1 year was equal for both groups, compared to 6 weeks postoperatively. In our experience after 90 postoperative days, the QoL in the two groups was similar ${ }^{[27]}$.

For what concern short-term oncological outcomes, in our experience, the two techniques resulted similar, no differences were observed for median number of lymph nodes harvested and Ro resection. In HIL group 2 patients presented a R1 resection (circumferential margin) and none in TMIIL group. The bias of this result is associated to a longer duration of laparoscopy for patients with bulky tumor of EGJ and consequently these patients were assigned to HIL group according to our methods.

The principal limit of our analysis is represented by small size of our group of patients treated with TMIIL esophagectomy, which, according to the current literature, is far from the learning curve plateau Beyond that, the power of our statistical analysis is limited by the comparison of two small groups of patients. One important element emerging from our analysis is that this anastomotic technique is safe and feasible, provided the technical details are meticulously followed.

In conclusion, TMIIL seems feasible and safe in skilled hands altought it represents a challenging procedure also for surgeons dedicated to esophagheal surgery and expert in minimally-invasive surgery. In our experience no differences were observed between the two groups, but principal limit of our analysis is represented by the small series of patients enrolled in this study and the lacking of randomization. Duration of surgery and anastomotic leaks represent the principal elements to evaluate the achieving of the plateau in the learning curve. Randomized control trials are not available and also retrospective analysis are lacking of comparison between TMIIL and HIL. Randomized controlled trials are necessary to confirm the good results evidenced in the current literature, evaluate long term oncological outcomes and create technical recommendations to approach this difficult technique avoiding a high rate of complications during the 
learning curve. Quality of life should also be evaluated in a randomized prospective setting as this element is considered one of principal issue in favor of a totally minimally invasive approach for IL esophagectomy.

\section{DECLARATIONS}

\section{Authors' contributions}

Conceived and designed the study: de Pascale S, Fumagalli Romario U

Implemented the study and drafted the article: de Pascale $S$

Made substantial contributions to the analysis of data: Ghidinelli F, Piccioli AN, Borin S

Substantially contributed to the interpretation of data, made critical revisions related to important intellectual content of the manuscript, and approved the final version of the manuscript: All authors

\section{Availability of data and materials}

Not applicable.

\section{Financial support and sponsorship}

None.

\section{Conflicts of interest}

All authors declared that there are no conflicts of interest.

\section{Ethical approval and consent to participate}

Patients were not required to provide informed consent to this study because the analysis used anonymous clinical data that were obtained after each patient agreed to treatment by written consent.

\section{Consent for publication}

Not applicable.

\section{Copyright}

(c) The Author(s) 2019.

\section{REFERENCES}

1. Luketich JD, Alvelo-Rivera M, Buenaventura PO, Christie NA, McCaughan JS, et al. Minimally invasive esophagectomy: outcomes in 222 patients. Ann Surg 2003;238:486-95.

2. Burdall OC, Boddy AP, Fullick J, Blazeby J, Krysztopik R, et al. A comparative study of survival after minimally invasive and open oesophagectomy. Surg Endosc 2015;29:431-7.

3. Haverkamp L, Seesing MF, Ruurda JP, Boone J, V Hillegersberg R. Worldwide trends in surgical techniques in the treatment of esophageal and gastroesophageal junction cancer. Dis Esophagus 2017;30:1-7.

4. Barkun JS, Aronson JK, Feldman LS, Maddern GJ, Strasberg SM, Balliol collaboration. Evaluation and stages of surgical innovations. Lancet 2009;374:1089-96.

5. Ergina PL, Cook JA, Blazeby JM, Boutron I, Clavien PA, et al. Challenges in evaluating surgical innovation. Lancet 2009;374:1097-104.

6. Hirst A, Philippou Y, Blazeby J, Campbell B, Campbell M, et al. No surgical innovation without evaluation: evolution and further development of the IDEAL framework and recommendations. Ann Surg 2019;269:211-20.

7. Lordick F, Mariette C, Haustermans K, Obermannová R. Oesophageal cancer: ESMO Clinical Practice Guidelines for diagnosis, treatment and follow-up. Ann Oncol 2016;27:v50-7.

8. Irino T, Tsai JA, Ericson J, Nilsson M, Lundell L, et al. Thoracoscopic side-to-side esophagogastrostomy by use of linear stapler-a simplified technique facilitating a minimally invasive Ivor-Lewis operation. Langenbecks Arch Surg 2016;401:315-22.

9. Low DE, Alderson D, Cecconello I, Chang AC, Darling GE, et al. International consensus on standardization of data collection for complications associated with esophagectomy: Esophagectomy Complications Consensus Group (ECCG). Ann Surg 2015;262:286-94.

10. Rizk NP, Bach PB, Schrag D, Bains MS, Turnbull AD, et al. The impact of complications on outcomes after resection for esophageal and gastroesophageal junction carcinoma. J Am Coll Surg 2004;198:42-50.

11. Gockel I, Kneist W, Keilmann A, Junginger T. Recurrent laryngeal nerve paralysis (RLNP) following esophagectomy for carcinoma. Eur J Surg Oncol 2005;31:277-81. 
12. van Workum F, Berkelmans GH, Klarenbeek BR, Nieuwenhuijzen GAP, Luyer MDP, et al. McKeown or Ivor Lewis totally minimally invasive esophagectomy for cancer of the esophagus and gastroesophageal junction: systematic review and meta-analysis. 2017;9:S826-33.

13. Degisors S1, Pasquer A, Renaud F, Béhal H, Hec F, et al. FREGAT working group. Are thoracotomy and/or intrathoracic anastomosis still predictors of postoperative mortality after esophageal cancer surgery? A nationwide study. Ann Surg 2017;266:854-62.

14. Mariette C, Markar SR, Dabakuyo-Yonli TS, Meunier B, Pezet D, et al. FREGAT working group. Hybrid Minimally Invasive Esophagectomy for Esophageal Cancer. N Engl J Med 2019;380:152-62.

15. Bizekis C, Kent MS, Luketich JD, Buenaventura PO, Landreneau RJ, et al. Initial experience with Minimally Invasive Ivor Lewis Esophagectomy. Ann Thorac Surg 2006;82:402-7.

16. Noble F, Kelly JJ, Bailey IS, Byrne JP, Underwood TJ. A prospective comparison of totally minimally invasive versus open Ivor Lewis esophagectomy. Dis Esophagus 2013;26:263-71.

17. Xie MR, Liu CQ, Guo MF, Mei XY, Sun XH, et al. Short-term outcomes of minimally invasive Ivor-Lewis esophagectomy for esophageal cancer. Ann Thorac Surg 2014;97:1721-7.

18. Chen X, Yang J, Peng J, Jiang H. Case-matched analysis of combined thoracoscopic-laparoscopic versus open esophagectomy for esophageal squamous cell carcinoma. Int J Clin Exp Med 2015;8:13516-23.

19. Sihag S, Kosinski AS, Gaissert HA, Wright CD, Schipper PH. Minimally invasive versus open esophagectomy for esophageal cancer: a comparison of early surgical outcomes from the society of thoracic surgeons national database. Ann Thorac Surg 2016;101:1281-9.

20. Tapias LF, Mathisen DJ, Wright CD, Wain JC, Gaissert HA, et al. Outcomes with open and minimally invasive Ivor Lewis esophagectomy after neoadjuvant therapy. Ann Thorac Surg 2016;101:1097-103.

21. Wang J, Xu M, Xie M, Mei X. Minimally Invasive Ivor-Lewis esophagectomy (MIILE): a single-center experience. Indian J Surg 2017;79:319-25.

22. Straatman J, van der Wielen N, Cuesta MA, Daams F, Roig Garcia J, et al. Minimally invasive versus open esophageal resection: threeyear follow-up of the previously reported randomized controlled trial: the TIME trial. Ann Surg 2017;266:232-6.

23. Qi W, Zixiang W, Tianwei Z, Shuai F, Sai Z, et al. Long-term outcomes of 530 esophageal squamous cell carcinoma patients with minimally invasive Ivor Lewis esophagectomy. J Surg Oncol 2018;117:957-69.

24. van Workum F, Stenstra M, Berkelmans G, Slaman AE, van Berge Henegouwen MI, et al. Learning curve and associated morbidity of minimally invasive esophagectomy: a retrospective multicenter study. Ann Surg 2019;269:88-94.

25. Mungo B, Lidor AO, Stem M, Molena D. Early experience and lessons learned in a new minimally invasive esophagectomy program. Surg Endosc 2016;30:1692-1698.

26. Woodard GA, Crockard JC, Clary-Macy C, Zoon-Besselink CT, Jones K, et al. Hybrid minimally invasive Ivor Lewis esophagectomy after neoadjuvant chemoradiation yields excellent long-term survival outcomes with minimal morbidity. J Surg Oncol 2016;114:838-47.

27. Maas KW, Cuesta MA, van Berge Henegouwen MI, Roig J, Bonavina L, et al. Quality of life and late complications after minimally invasive compared to open esophagectomy: results of a randomized trial. World J Surg 2015;39:1986-93. 